\title{
Princípios, regras e ponderação: uma polêmica no âmbito da teoria discursiva do direito
}

\author{
Principles, RUles ANd Weighting: \\ A CONTROVERSY WITHIN THE DISCURSIVE \\ THEORY OF LAW
}

\author{
Cláudio Ladeira de Oliveira *
}

Resumo: Este artigo analisa o debate travado entre autores vinculados à "teoria discursiva do Direito". Inicialmente, demonstra o modo como Jürgen Habermas, apoiando-se nos argumentos de Klaus Günther, rejeita a tese de Robert Alexy sobre a distinção estrutural entre princípios e regras $\left(\mathrm{T}_{\mathrm{PR}}\right)$. Em seguida, expõe o modo como Habermas rejeita a "tese da ponderação", sustentada por Alexy como solução de conflito entre princípios $\left(\mathrm{T}_{\mathrm{PV}}\right)$. Por fim, extrai algumas conclusões desta polêmica.

Palavras-chave: Princípios. Regras. ponderação de valores. Jürgen Habermas. Robert Alexy.

Abstract: This article analyses the debate between authors belonging to the "discursive theory of law". First, it shows how Jürgen Habermas, relying on the arguments of Klaus Günther, rejects the thesis of Robert Alexy on the structural distinction between principles and rules $\left(\mathrm{T}_{\mathrm{PR}}\right)$. Then outlines how Habermas rejects the "weighting thesis ", supported by Alexy as a solution of a conflict between principles. Finally, it

* Cláudio Ladeira de Oliveira, Professor adjunto da Faculdade de Direito da Universidade de Brasília - UnB. Ex-professor da faculdade de direito da Universidade Federal de Juiz de Fora (UFJF) e do Curso de Direito Universidade Estadual de Londrina (UEL). Possui doutorado e mestrado em Direito pela Universidade Federal de Santa Catarina, tendo realizado estágio de doutoramento na Universidade de Lisboa, e graduação em Direito pela Universidade Federal de Mato Grosso (1995). E-mail: claudioladeira@hotmail.com draws some conclusions of this controversy.

Keywords: Principles. Rules. Weighting. Jürgen Habermas. Robert Alexy. 


\section{INTRODUÇÃO}

Neste artigo serão tratadas divergências teóricas que são, por assim dizer, “domésticas" (HABERMAS, 1999, p. 447), uma vez que os principais fundamentos teóricos são amplamente compartilhados pelos autores aqui discutidos, expoentes da chamada "teoria do discurso", especialmente Jürgen Habermas, Robert Alexy e Klaus Günther. As divergências apontadas restringem-se à atividade de interpretação e aplicação das normas jurídicas. Por um lado, o próprio Habermas reconhece o mérito de Alexy haver introduzido a teoria discursiva no direito, chamando sua atenção para o problema e ajudandoo a "compreender a dialética da liberdade e igualdade na interpretação dos direitos fundamentais" (HABERMAS, 1998, p. 428). Por sua vez, Alexy foi

o primeiro a formalizar em regras grande parte das condições discursivas elaboradas na teoria habermasiana. Posteriormente, o próprio Habermas recuperou algumas destas regras - as regras do discurso racional sobre questões práticas - de acordo com seus próprios interesses sistemáticos (ARROYO, 2000, p. 126).

Os vínculos são sempre ressaltados como um aporte simultâneo de interpretação e extensão da teoria discursiva, a partir do qual ela pode desenvolver temas até então ignorados, mas para os quais oferecia idéias frutíferas: "a teoria de Alexy significa, por um lado, uma sistematização e reinterpretação da teoria do discurso prático habermasiana e, por outro, uma extensão desta tese para o campo específico do direito.” (ATIENZA, 2000, p. 234).

\section{A TESE DA DISTINÇÃO “ESTRUTURAL” ENTRE PRINCÍPIOS E REGRAS ( $\mathrm{T}_{\mathrm{PR}}$ )}

Seja na teoria do direito seja na legislação, há muito tonou-se comum a afirmação de que a jurisprudência deve levar em conta não apenas "regras", cuja interpretação se encontra fora de controvérsias, mas também "princípios", cuja aplicação demanda o uso de argumentos às vezes bastante complexos ${ }^{1}$. De um lado a menção legislativa aos "princípios gerais do direito", como por exemplo aquela realizada pela Lei de Introdução às Normas do Direito Brasileiro ${ }^{2}$

\footnotetext{
${ }^{1}$ Para uma extensa abordagem do tema, Ávila (2004).

${ }^{2}$ Decreto-Lei $\mathrm{n}^{\circ} 4.657$, de 4 de Setembro de 1942, art. $4^{\circ}$ : "quando a lei for omissa, o juiz decidirá o caso de acordo com a analogia, os costumes os princípios gerais do direito".
} 
na esteira de similares dispositivos em inúmeras codificações da Europa continental $^{3}$, e de outro construções teóricas como as de Esser (1961), são apenas partes mais visíveis de uma vasta série de teses e decisões a sustentar a existência de um tipo especial de normas jurídicas, os "princípios". No entanto, a familiaridade do uso desta noção não se fez acompanhar de consenso quanto aos aspectos mais elementares de sua definição, como natureza, conteúdo, o papel que devem desempenhar na atividade jurisprudencial e sua importância política (MUÑIS, 1997, p. 267). Apenas a título de exemplo, uma breve e inconclusiva recensão feita por Atienza e Manero identifica oito acepções possíveis para "príncipios" em uso na teoria do direito e na jurisprudência (ATIENZA; MANERO, 1991): (i) Princípio como norma extremamente genérica, caso em que as propriedades relevantes reguladas pela norma (princípio) em questão são muito gerais. Citam o exemplo do art. 1.091 do Código Civil espanhol, que dispõe: "las obligaciones que nacen de los contratos tienen fuerza de ley entre las partes contratantes, y deben cumplirse al tenor de los mismos". (ii) princípio no sentido de uma norma que utiliza conceitos juridicos indeterminados, tais como as normas que pró́bem o "abuso de direito"; (iii) princípio como norma programática; (iv) princípio como norma que estabelece "valores superiores" do ordenamento jurídico, como a igualdade entre todos os cidadãos; (v) princípio como norma de grande relevância jurídica, ainda que sua formulação seja bastante exata (a exemplo de algumas das imunidades tributárias previstas no art. 150 da Constituição da Republica); (vi) princípio como norma jurídica de hierarquia elevada; e (vii) como norma dirigida aos órgãos de aplicação do direito, tais como as que proíbem a analogia em matéria tributária (BRASIL, 1966. art. 108, $\S 1^{\circ}$ ); e por fim (viii) princípio como "enunciado ou máxima da ciência jurídica de considerável grau de generalidade e que permite a sistematização do ordenamento jurídico ou de algum setor do mesmo" (ATIENZA; MANERO, 1991, p. 105)

No entanto, se bem que antiga e variada, é possível afirmar que o debate sobre a distinção entre princípios e regras adquiriu suas feições atuais a partir da intervenção de Ronald Dworkin que, em ensaio de 1967 ("The Model of Rules") no qual dirigia sua crítica ao positivismo de Hart ${ }^{4}$, reivindicou para "regras" e "princípios" uma diferença de natureza "lógica" (DWORKIN, 2002, p. 39). Sob aspectos fundamentais os argumentos que oferece para sustentar a

\footnotetext{
${ }^{3}$ A exemplo do Código Civil austríaco de 1811, que determinava que nos casos duvidosos fosse apoiada a decisão nos "princípios do direito natural" (MUÑIS, 1997, p. 267).

${ }^{4}$ Ensaio este posteriormente recolhido em Dworkin (2002, ps. 23-125), também Hart (1994).
} 
distinção são similares aos utilizados na obra de W. D. Ross, "The Right and the Good" (1988), o que no entanto não permite ignorar que foi mesmo com Dworkin que tal distinção foi incorporada à teoria jurídica reivindicando para sí um status lógico especial, até encontrar em Robert Alexy uma densidade antes inédita.

Em seu "ataque geral contra o positivismo", Dworkin afirma que na argumentação jurídica são encontrados "padrões" (standards) de distintas espécies, entre eles aqueles que funcionam como "regras" (rules), os que funcionam como "princípios" (principles) ou ainda como "políticas" (politics). ${ }^{5}$ Entre princípios e políticas, ainda que o próprio Dworkin afirme usar tais termos de modo muitas vezes intercambiável, há uma importante distinção. Política é definida como um tipo de padrão que estabelece um objetivo social a ser alcançado, como por exemplo a promoção do crescimento econômico, a redução do desemprego e a redução dos acidentes de trabalho. Por sua vez, princípios são definidos como o tipo de padrão que formula uma "exigência da justiça ou equidade ou alguma outra dimensão da moralidade" e que deve ser observada em virtude de seus próprios termos e não porque é capaz de promover algum estado de coisas visto como socialmente desejável. No exemplo do próprio Dworkin, o padrão segundo o qual "ninguém deve beneficiar-se de sua própria torpeza" é um princípio, ao passo que o padrão que estabelece que acidentes automobilísticos devem ser reduzidos é uma política.

Mas o que interessa mesmo a Dworkin é a oposição entre princípios em sentido genérico (ou seja, incluindo políticas) e regras. Para ilustrar esta importante distinção Dworkin apóia-se em decisões judiciais extraídas de tribunais norte-americanos. É muito importante prestar atenção nos “princípios" identificados por Dworkin pois isso permitirá uma correta compreensão de sua tese bem como da importante diferença que há entre seus argumentos e os de Alexy. Vejamos os princípios:

(a) "devemos ter em mente o princípio geral de que, na ausência de fraude, aquele que não le o contrato antes de assiná-lo não pode, mais tarde, minimizar seus encargos." (b) "na aplicação deste princípio, o preceito básico da liberdade das partes competentes para contratar é um fator importante" (c) "a liberdade de contratar não é uma doutrina tao imutável a ponto de não admitir nenhuma ressalva na área que nos concerne" (d) "em uma sociedade com a nossa, na qual o automóvel é um acessório comum e necessário à vida

${ }_{5}$ Para o que se segue Dworkin (2002, ps. 35-72). 
cotidiana e na qual o seu uso é tao cheio de perigos para o motorista, os passageiros e o público, o fabricante tem uma obrigação especial no que diz respeito à fabricação, promoção e venda de seus carros. Consequentemente, os tribunais devem examinar minuciosamente os contratos de compra para ver se os interesses do consumidor e do público estão sendo tratados com equidade" (e) "existe algum princípio que seja mais familiar ou mais firmemente inscrito na historia do direito anglo-americano do que a doutrina basilar de que os tribunais não se permitirão ser usados como instrumentos de iniquidade e injustiça?" (f) "mais especificamente, os tribunais em geral excusam a prestar-se a garantir a execução de uma «barganha» na qual uma parte aproveitou-se injustamente das necessidades econômicas da outra..." (DWORKIN, 2002, ps. 38-39)

Logo adiante será realçada a distinção que há entre estes princípios elencados por Dworkin e a definição de princípios fornecida por Robert Alexy. Por ora é importante realçar que se trata aqui de "padrões" que enunciam máximas as quais não se encontram necessariamente explicitamente fixadas em algum dispositivo jurídico como uma constituição ou código. Aparecem sob a forma de juízos de aplicação, a caso concreto, de princípios gerais similares a uma das definições fornecida por Atienza e Manero: princípio como "enunciado ou máxima da ciência jurídica de considerável grau de generalidade e que permite a sistematização do ordenamento jurídico ou de algum setor do mesmo." (ATIENZA; MANERO, 1991, p. 105). Neste sentido trata-se de princípios que já são interpretações (reconstruções) da massa do direito vigente, oferecido para justificá-lo moralmente. (DWORKIN, 1999)

Dworkin (2002, p. 39) afirma que "a distinção entre princípios jurídicos e regras jurídicas é de natureza lógica", ainda que a distinção fique evidente apenas quando é examinado o modo de funcionamento das regras e princípios. A formulação do critério de distinção é conhecida: a aplicação das regras, tais como as que estabelecem o limite máximo de velocidade de cinquenta quilómetros por hora em determinada via, ocorre à maneira do "tudo ou nada". Dada uma determinada regras, ou ela não é valida, e nesse caso deve ser afastada, ou é válida e deve ser aplicada, ou ainda é valida mas comporta algum tipo específico e delimitado de excepção. (DWORKIN, 2002, p. 39). Uma vez reconhecido com válida a regra que estipula o limite de velocidade, ou ela é observada ou é fixada uma excepção. E se duas regras conflitam, uma delas não pode ser válida ou há exceção. Não é o que ocorre com a aplicação de princípios, pois nos casos em que tratamos de padrões como "ninguém pode 
se beneficiar de sua própria torpeza", os quais não pretendem "estabelecer condições que tornem sua aplicação necessária" (DWORKIN, 2002, p. 41). Um princípio enuncia uma razão que influencia o argumento em determinada direção, mas a aplicação do princípio permanece na dependência de uma decisão particular. Afinal, princípios possuem uma dimensão ignorada pelas regras: peso ou importância. ${ }^{6}$

Não é a forma assumida pelo padrão que permite concluir tratar-se ele de um princípio ou de uma regra, muitas vezes ela pode dar margem à confusão. Em casos assim, por mais que Dworkin houvesse afirmado ser lógica a distinção, ela deve ser auferida por referência ao contexto concreto de aplicação, ao conjunto das instituições da prática de determinada comunidade juridica:

'Um testamento é invalido a menos que seja assinado por três testemunhas' não é muito diferente, quanto à forma, de "um homem não poderá beneficiarse de seus atos ilícitos", mas quem conhece o direito norte-americano sabe que deve considerar a primeira frase como a expressão de uma regra e a segunda como expressão de um princípio. (DWORKIN, 2002, p. 43).

Mas se é realmente assim, será realmente lógica a distinção? Ainda que tenha sido bastante divulgada, o próprio Dworkin não mais retorna, em seus textos posteriores, à distinção entre princípios e regras. Certamente ela não é negada porém não encontra espaço relevante na formulação de suas teses principais a partir do final dos anos 1970. É Robert Alexy quem, em 1986, retorna a tal distinção por ocasião de sua tentativa de reconstruir aspectos importantes da jurisprudência do Tribunal Constitucional Federal alemão (ALEXY, 1993). Alexy apresenta $T_{P R}$ como uma reconstrução racional, com os meios da teoria discursiva do direito, do procedimento de aplicação dos direitos fundamentais levada a cabo pelo Tribunal Constitucional Federal alemão, o qual interpretaria o catálogo constitucional de direitos como expressão de uma "ordem concreta de valores" (ALEXY, 1994b, p. 159-177). Esta construção teórica do tribunal seria passível de críticas, pois permitiria uma substituição do caráter normativo da constituição em benefício das opções axiológicas do próprio tribunal, curto-circuitando as actividades judicial e legislativa (ALEXY, 1994b,

\footnotetext{
${ }^{6}$ Trata-se de uma afirmação tão popular entre teóricos do Direito que mesmo um crítico contundente da teoria jurídica de Dworkin, como Jeremy Waldron, declara aceitá-la sem maiores problemas: "I [...] see little to quarrel with in what He says about the logical character of the contribution that principles and policies make to legal argument: He talks of the dimension of 'wheight', wich distinguishes their contributioin from the contribution made by rules" (WALDRON, 2006, p.158).
} 
p. 161), de modo que uma interpretação adequada substituiria a interpretação de "valores" por "princípios", enquanto normas estruturalmente distintas das regras (ALEXY, 1994b, p. 165 e 175): seu objetivo seria "impor um modelo racional ao processo de ponderação" utilizado pelo tribunal (GÜNTHER, 2001). Não cabe, no curto espaço deste capítulo, fazer justiça ao debate constitucional, mas tão-somente fixar o argumento essencial da distinção crucial para TPR.? Ao mesmo tempo Alexy pretende que sua distinção seja conceitualmente mais rigorosa que as várias fórmulas até então encontradas na teoria jurídica e na jurisprudência, especialmente aquela formulada por Dworkin. ${ }^{8}$ No entanto os termos em que o faz deram origem a uma disputa relevante quanto à correta fixação do conceito de princípios entre autores vinculados à ética discursiva.

Princípios e regras são as duas espécies distintas de normas jurídicas, ambos possuindo validade normativa, um conceito que não sofre "graduação": normas em geral ou são válidas ou não. A diferença entre ambas é questão não apenas de grau ou generalidade de sua formulação mas sim "qualitativa": "toda norma ou é uma regra ou um princípio.” Os princípios contém mandamentos que não são definitivos mas apenas "prima facie", pois ordenam que algo seja realizado na maior medida possível, observados os limites das possibilidades jurídicas e fáticas: princípios são nesse sentido "mandamentos de optimização.". A obediência a um princípio é uma questão de grau, e os termos exatos de seu cumprimento em casos concretos de decisão é algo que dependem dos fatos e de outras normas jurídicas que possivelmente também incidem sobre a matéria. Por sua vez as regras desconhecem a variabilidade no grau de seu cumprimento: regras ou são observadas ou são desobedecidas. A exigência que elas contêm deve ser integralmente observada, sem margem a graduações em seu cumprimento. (ALEXY, 1993, p.88-101).

O modo mais elucidativo de demonstrar esta distinção é, para Alexy, o estudo dos casos de conflito de regras e colisões de princípios. Quando duas regras conflitam entre sí a solução consiste na introdução de uma regra de excepção ou na declaração de invalidade de ao menos uma das duas regras. Neste caso a decisão sobre a correta aplicação dos dispositivos normativos em conflito é sempre uma questão sobre a validade jurídica dos mesmos (ALEXY (1993, p. 88). De outro lado a colisão entre princípios não há disputa quanto à

\footnotetext{
${ }^{7}$ Para argumentos semelhantes aos de Alexy, e que poderiam ser igualmente atingidos pelas objeções de Searle e Günther, ver Peczenik (1989, p.58-96, 418-425).

${ }^{8}$ Para o que se segue, Alexy (1993).
} 
validade de ambos, a qual é aceita, mas sim quanto à dimensão do "peso" específico que cada um deles possui. Ocorre apenas que um deles deve "ceder" diante do outro, no caso concreto. É estabelecida uma relação de preferência condicionada entre os princípios (este ponto é objeto do próximo item deste capítulo). Assim um conflito entre duas regras, uma das quais proíbe a circulação de veículos no parque e outra que regula o uso de ambulâncias para a prestação do socorro aos enfermos, especialmente num caso em que um cidadão sofre um ataque cardíaco durante um passeio no parque, tal conflito pode ser solucionado graças à inclusão de uma "cláusula de excepção". Caso uma regra permita o protocolo de um recurso até o quinto dia útil posterior à intimação da decisão, e outra regra determine que o prazo para o mesmo recurso é de três dias, uma das duas não pode ser válida. Mas se o conflito existe entre princípios que estabelecem uma proteção à liberdade de imprensa e informação e outro que garante o direito à informação, aceita-se a validade de ambos os princípios porém, diante das condições fáticas e normativas concretas, é estabelecida uma relação de preferência condicionada, mediante a qual um dos dois, devido a seu maior peso, "cede" frente ao outro, no caso concreto.

A tese de que há entre princípios e regras uma distinção lógica-estrutural $\left(\mathrm{T}_{\mathrm{PR}}\right)$, especialmente tal como formulada por Robert Alexy, tem sido contestada por Klaus Günther (2001), apoiando-se em argumentos lançados por John Searle (1978). Em virtude da importante divulgação que esta tese recebeu na doutrina constitucional e mesmo na jurisprudência, convém atentar para os termos da crítica que lhe é dirigida (SILVA, 2002, p. 23-50). Ambos contestam a distinção "estrutural" entre normas definitivas e prima facie como resultado de uma compreensão equivocada de duas formas distintas de juízos sobre normas. Em síntese, é um equívoco afirmar que princípios estabelecem comandos "prima facie" e regras comandos definitivos, pois todas as normas são prima facie válidas e comandos definitivos são sempre o resultado de juízos de aplicação de normas a casos concretos. Vejamos o exemplo clássico: $\mathrm{X}$ promete $\mathrm{a} \mathrm{Y}$ ir à sua festa de aniversário, mas chegada a hora da festa um vizinho, gravemente enfermo, implora por socorro. Deve dirigir-se à festa tal como havia prometido ao amigo, ignorando o pedido de auxílio, ou deve auxiliar o vizinho levando-o ao hospital, descumprindo a promessa inicialmente realizada? A mais famosa variação deste "dilema" moral encontra-se já em Kant (1995, p. 173-179), em sua rejeição de um suposto direito à mentira motivado por causas nobres: um assassino está a perseguir um inocente o qual se refugia na casa de um terceiro e a este o assassino pergunta sobre o paradeiro da vítima. $O$ terceiro encontrase diante de um conflito entre regras morais: "deves falar a verdade" e "deves 
ajudar às pessoas". Não se trata aqui de avaliar filosoficamente a tese kantiana, a qual já foi reputada como pura "tolice" (SEARLE, 2002, p. 63), indigna de maior atenção, mas apenas do problema da correta definição do conflito moral em questão. O modo como autores como Ross pretendem solucioná-lo é inserindo uma distinção conceitual entre tipos de obrigação prima facie e definitiva, e aqui reside o problema criticado por Searle e, seguindo-o, também por Günther.

Searle identifica duas acepções em Ross e outros autores que compartilham semelhante definição ${ }^{9}$. No primeiro caso, obrigações prima facie válidas apenas parecem estabelecer uma obrigação, sem que o façam realmente, ao passo que obrigações atuais vinculam verdadeiramente uma obrigação. A afirmação "1. $X$ tem um obrigação prima facie de fazer $A$ " não implica que " 2 . $\mathrm{X}$ tem uma obrigação de fazer A" porque ela é consistente como " 3 . X não possui nenhuma obrigação real de fazer $\mathrm{A}$, ele apenas parece possuir tal obrigação". Para Searle esta acepção deve ser prontamente rejeitada uma vez que é incapaz de expressar o fato muito cotidiano de que podem haver conflitos reais entre obrigações morais: se obrigações surgem apenas como resultado de juízos concretos de aplicação, então seria o mesmo que afirmar que, sendo preferida a norma que recomenda o auxílio às pessoas, sequer houvesse surgido alguma obrigação resultado da promessa realizada. Seria como se ela simplesmente não houvesse sido feita, por incapaz de gerar uma obrigação.

A segunda acepção identificada por Searle opõe obrigações prima facie e absolutas, e é similar àquela utilizada por Alexy pois insere uma relação de precedência lógica ente dois tipos de obrigação: uma que é prima facie e goza de um status hierarquicamente inferior às obrigações definitivas. Uma obrigação prima facie não deixa de existir mesmo quando é afastada por obrigações absolutas, ela apenas pertence a uma classe de obrigações inferiores - por mais fracas, podendo ser reconhecida em algum caso concreto quando for capaz de afastar todas as demais obrigações que incidem sobre uma mesma situação. Mas neste caso a decisão sobre o caráter prima facie ou absoluto da obrigação dependeria da situação particular de conflito, pois obrigações que numa dada situação assumem um caráter absoluto poderiam no futuro surgir em outras situações como prima facie. Mas como então distinguir entre dois tipos de normas, um estabelecendo obrigações prima facie e outro absolutas antes de uma situação concreta de aplicação? O núcleo da tese de Searle consiste em distinguir dois tipos de proposições sobre obrigações, um particular (“9. Brown está obrigado a fazer $A$ porque ele prometeu fazer $A$ ") e outro

\footnotetext{
${ }^{9}$ Para o que se segue Searle (1978, p.81-90).
} 
genérico ("10. Todas as promessas criam obrigações”). A questão é que afirmações como 9 podem assumir um caráter prima facie ou absoluto dependendo do caso concreto, ao passo que todas aquelas semelhantes a 10 são sempre prima facie, já que "toda obrigação está sujeita a ser afastada por considerações especiais em circunstâncias particulares".

Uma terceira interpretação, proposta pelo próprio Searle, demonstra o equívoco que ele identifica na acepção anterior e recomenda a substituição da expressão prima facie por conceitos que evitam as dubiedades apontadas. Ao invés de uma distinção ontológica entre tipos de obrigação ele sugere uma distinção entre tipos de juízos deontológicos sobre as obrigações existentes. Para Searle é importante distinguir entre os seguintes tipos de afirmações:

(a) João tem uma obrigação de fazer $A$. [...]

(d) João deve, tudo o mais permanecendo igual, fazer $A$.

(e) João deve fazer $A$.

(f) Todas as coisas consideradas, João deve fazer $A$.

(g) Todas as coisas consideradas, João não deve fazer $A$.

(h) João tem uma obrigação de não fazer $A$.

A fonte de muitas confusões teóricas reside no desconhecimento de que, se por uma lado afirmar (a) vincula com (d), por outro lado (a) não apenas não vincula com (f) como também é coerente com a afirmação (g). A questão é portanto que é possível, em situações de conflito normativo, possuir uma obrigação válida (ex. não mentir) mas ao mesmo tempo, uma vez considerada a "máxima quantidade de informação relevante" sobre a situação, não realizar aquilo que a obrigação em questão prescreve. Afirmar (a) implica em (d), porque obrigações fornecem razões de um tipo especial para justificar determinadas ações e o "deve" de (d) expressa tais razões, e por isso também dizer (a) é um modo indireto de afirmar (e). A passagem de (a) para (f) ou (g) corresponde à passagem de (9) a (10), e é alcançada mediante "princípios da conversação" (uma ideia a partir da qual Günther construirá sua tese do princípio de adequação) e não graças a caracteres semânticos especiais de obrigações estruturalmente diversas: "esta distinção permanece clara no uso ordinário da linguagem e não requer a introdução do termo prima facie para ressaltá-la." (ALEXY, 1993, p. 89).

Esta distinção, as possíveis confusões e o modo correto de expressála, é formalizada por Searle do seguinte modo: para a existência de obrigações 
do tipo expresso em (a) é usado $\mathrm{O} 1, \mathrm{O} 2, \mathrm{O} 3 \ldots$ On, e para juízos deontológicos como (f) é usado $\mathrm{O}^{*}$. A afirmação de que há a conjugação entre várias tipos de (a) e (g) é então simbolizada como "11. O1p \& O2p \& $\mathrm{O}^{*} \sim$ p" e a conjunção de (a) e (h) é simbolizada como "12. O1p \& O2 p". Com isso Searle pretende afastar a possibilidade de inconsistência lógica porque as seguintes duas formas de expressão estão equivocadas: "13. O1p à $\sim 02 \sim p "$ e "14. O1p à $\sim \mathrm{O}^{*} \sim \mathrm{p}$ ". O equívoco de 13 consiste em negar a possibilidade da existência simultânea de obrigações conflitantes ao passo que 14 erra ao negar que alguém possa estar sob uma obrigação validade de fazer algo e, ao mesmo tempo, todas as coisas consideradas, deva se abster de fazer esta mesma coisa. Uma forma correta seria “15. O*p à $\sim p$ ", que expressa uma situação na qual alguém possui uma obrigação válida particular mas que, todas as coisas consideradas, deve abster-se da ação prescrita, sem que por isso (a) deixe de expressar uma obrigação "plena, incondicional" (SEARLE, 2000, p. 223). Assim, ao invés de distinguir entre formas de obrigação (normas prima facie e absolutas) Searle propõe uma distinção entre formas de juízos deontológicos: os que certificam a existência de obrigações e afirmações sobre o que deve ser feito, todas as coisas consideradas.

prima facie és un modificador epistémico de oraciones, no un predicado de tipos de obligación, y no podria ser un termino apropiado para describir el fenômeno de las obligaciones en conflicto allí donde una es superada por la otra. La teoría de las obligaciones prima facie es algo peor que mala filosofia, es mala gramática. (SEARLE, 2000, p. 223).

Apoiado nestes argumentos, Günther objeta ainda que o modo como Alexy defende a tese não permite compreender por que os discursos de aplicação são exigidos pela "estrutura" dos princípios e não das regras, quando isso seria uma exigência para todos os casos de aplicação de normas. Apenas depois que houvéssemos descrito a situação de modo adequado seria possível concluir pela existência ou não de uma obrigação concreta de agir, apoiados nas regras previamente interpretadas. ${ }^{10}$

\footnotetext{
10 "It remains unclear why this type of appropriateness argumentation should be prescribed by the structure of principles. That certain norms require appropriateness argumentation only becomes apparent in application situations themselves. The requirement that a norm be applied relative to the actual and normative (legal) possibilities in a situation can however be directed at every norm. it does not depend on the norm itself whether we apply it with or without consideration of the particular circumstances of a situation." (GUNTHER, 2001, p.216).
} 
O erro de Alexy consistiria em unificar duas proposições deontológicas diversas: "x deve fazer y", e "após todas as coisas serem consideradas, $x$ deve fazer y". No entanto, não haveria sentido em atribuir o caráter de definitivo antes que pudéssemos verificar se conflita com outras regras "nos conferiríamos um caráter definitivo a uma norma porque a consideramos apropriada em situações que podemos compreender claramente.” (GUNTHER, 2001, p 217). Quando em situações concretas aplicamos normas num sentido "absoluto" isso ocorre porque já consideramos as circunstâncias relevantes, e portanto "the distinction between principles and rules is not a distinction within the concept of norm, but one within the presuppositions of action on which norms are applied" (GUNTHER, 2001, p 217). Não se trata de distintas estruturas (entre princípios e regras) mas sim de usos diferentes das normas jurídicas. E Alexy não faz justiça à crítica quando a interpreta como se fora uma afirmação de que "apenas normas existem" (ALEXY, 2000, p. 299) e princípios não existissem. Ora, o que Günther afirma, apoiado na tese de Searle, é que não há uma peculiaridade na estrutura das normas que permita a classificação entre normas que estabelecem comandos de optimização e normas que estabelecem obrigações definitivas, mas sim uma distinção entre o uso de regras em discursos de fundamentação de normas e de aplicação, no qual são consideradas todas as características da situação. Isso não implica em rejeitar a existência de "princípios", ou ainda, em afirmar a exclusividade das regras, como normas que estabelecem obrigações definitivas, e certamente não é o caso em Günther. Sua tese é compatível com a idéia de que há normas jurídicas mais abstratas porém cuja validade é a mesma das regras; e mais que isso, especialmente se por "princípios" consideramos argumentos que reconstróem parcialmente alguns aspectos do ordenamento jurídico segundo uma perspectiva moral, por exemplo como faz Dworkin. O problema de Alexy consiste em que sua defesa da distinção estrutural permanece dependente de uma opção entre dois tipos de classificação das normas jurídicas em geral e dos direitos fundamentais em particular, classificação esta que, por unilateral, sutilmente carrega consigo a tese que Alexy pretende defender. Isso ocorre porque Alexy apresenta as opções de um modo tal que induz a opção por sua perspectiva: as normas apenas podem ser definidas (i) como consistindo exclusivamente em regras, no sentido de obrigações definitivas que, especialmente no caso dos direitos fundamentais, definem posições individuais oponíveis contra o Estado, ou (ii) como consistindo em dois tipos de normas estruturalmente distintas, divididas em regras (obrigações definitivas) e princípios (comandos de optimização) (ALEXY, 2003a). Ora, se 
a opção (ii) é rejeitada - como é por Searle/Günther, isso não significa estar obrigado a aceitar (i)! Sobretudo a objeção de Alexy perde sentido se observamos que, para Günther, obrigações definitivas apenas surgem após a consideração das circunstâncias relevantes, ou seja, como resultado de discursos de aplicação de normas. Ainda que uma norma seja criteriosamente precisa na obrigação que estabelece não é possível assegurar-se contra a totalidade dos casos futuros de aplicação, cujas circunstâncias especiais podem recomendar seja aceita uma excepção. E com isso não se obriga a uma definição tao restrita de normas como em (i).

\section{UMA FORMULAÇÃO ALTERNATIVA DA TESE DA "DIFERENÇA ESTRUTURAL"}

Aulis Aarnio tentou solucionar esta disputa apresentando uma espécie de meio-termo entre teorias que são, segundo ele, unilaterais (AARNIO, 1997, 2002). Seja a tese da distinção estrutural entre princípios e regras (tal como é apresentada por Alexy), seja a de uma mera distinção de graus de abstração (como parece ser admitida por Günther), ambas devem ser recusadas. Para alcançar sua solução o primeiro passo consiste em aceitar o que há de correto nos duas teses conflitantes (AARNIO, 2002, ps. 174 e ss): da tese da distinção "forte" (estrutural) pretende preservar a definição de princípio como uma norma peculiar por que não resguarda obrigações definitivas, possui uma dimensão de "peso", são mandatos de optmização; da tese da distinção "fraca" reconhece o fato de que há também uma variação de generalidade com que são formulados os termos dos dois tipos de normas, o que uma correta classificação deve preservar. O segundo passo consiste em apresentar uma classificação alternativa para as normas jurídicas que mantém, simultaneamente, uma diferença de grau e qualidade entre princípios e regras: (i) as regras strictu senso (R), são os casos mais exemplares de "obrigações definitivas", caso exemplar de regras formuladas em termos tais que seu cumprimento pode ser submetido a juízos de "tudo ou nada", como uma norma que estabelece um prazo recursal específico; (ii) os "princípios semelhantes a regras" (PR), normas que embora similares a princípios em sua formulação submetem-se igualmente a um juízo de "tudo ou nada", como o "princípio" que proíbe a qualquer um aproveitar-se de sua própria torpeza, ou que estabelece a liberdade de expressão; (iii) as "regras semelhantes a princípios" (RP), regras cujo âmbito de aplicação é flexível e sujeito a valorações e interferências de outros princípios; (iv) os princípios strictu senso, 
tipo no qual incorrem as normas que estabelecem metas ou são cognitivamente abertas a valorações, tais como o princípio da "boa fé" nas relações contratuais.

Em terceiro lugar, Aarnio acrescenta a distinção entre prima facie (PF) e consideradas-todas-as-coisas (CTC) para representar, respectivamente, os momentos anterior e posterior à interpretação da situação que "concretiza" o significado de normas jurídicas em casos específicos de aplicação. Assim, normas como R e PR são capazes de especificar claramente obrigações graças a seu sentido PF mais definido, e portanto oferecem uma solução imediata às questões jurídicas controversas. Por sua vez, um princípio PF ambíguo só pode servir como apoio para decisões que devem ser tomadas após CTC. A escala que vai de $\mathrm{R}$ a $\mathrm{P}$ reflete um grau decrescente de clareza no dispositivo considerado: no pólo mais definido a norma já contém obrigações PF; no mais abstrato na norma só apresenta obrigação após CTC. R e PR já obrigam PF, ao passo que P e RP somente obrigam após CTC. Com esta conclusão Aarnio pode ser atingido pelas mesmas observações de Searle/Günther, já que, ao fim e ao cabo, reproduz a distinção entre normas que contém obrigações prima facie e normas que obrigam apenas depois que todas as características situacionais são levadas em conta. Na verdade Aarnio apenas acrescenta maiores detalhes a uma nomenclatura que se apoia numa distinção esta sim problemática e carente de elucidação.

\section{A TESE DA "PONDERAÇÃO DE VALORES" COMO SOLUÇÃO DE CONFLITO ENTRE PRINCÍPIOS $\left(\mathrm{T}_{\mathrm{PV}}\right)$}

Se a diferença estrutural entre princípios e regras é recusada, então o mesmo deve ocorrer em relação à tese da "ponderação". Note-se que mesmo havendo apresentado a diferença entre princípios e regras como sendo de natureza estrutural, o fato é que a oposição entre ambos é feita sempre por ocasião da aplicação de normas (GUNTHER, 2001, ps. 207 e ss). Alexy apresenta a distinção estrutural como forma de justificar um procedimento de ponderação que, já existindo nos tribunais alemães, ele pretende reconstruir. Sendo assim ocorre algo peculiar, já que ele não "constata" a existência de estruturas normativas logicamente diferentes para depois alcançar um correto modelo de solução de conflitos de princípios. Ao contrário, a elaboração filosoficamente sofisticada de um modelo de "ponderação" já intuitivamente praticado por tribunais é que exige, como uma de suas etapas, que uma distinção estrutural entre regras e princípios possa ser demonstrada. Não seria portanto 
o inverso a ocorrer, ou seja, Alexy não haveria alcançado o modelo de ponderação como forma de solucionar o problema surgido com o conflito de princípios estruturalmente distintos de regras.

Mas em que consiste afinal o modelo de "ponderação", e qual é o problema apontado por Habermas? Desde o início dos anos 1980 Alexy progressivamente tem desenvolvido o modelo da ponderação de valores para solucionar conflitos de princípios, o qual apresenta como uma reconstrução de aspectos da jurisprudência constitucional alemã. ${ }^{11}$ A ponderação seria uma parte do princípio da proporcionalidade, o qual consistiria em três subprincípios: o de "suitability", o da necessidade e o de proporcionalidade em sentido estrito, dos quais apenas o último interessa ao presente tópico. Supondo dois princípios (mandamentos de optimização) que entram em conflito num caso concreto, cumpre ponderar o conflito recorrendo ao sub-princípio da proporcionaliade em sentido estrito, o qual é idêntico à "lei da ponderação" (LP), capaz de expressar a idéia de optimização em relação às possibilidades jurídicas envolvidas, e que estabelece: "quanto maior é o grau da não satisfação ou de afetação de um princípio, tanto maior tem que ser a importância da satisfação do outro" (ALEXY, 1993, p. 161)

Habermas rejeita nessa construção, cujo ponto de partida é a $\mathrm{T}_{\mathrm{PR}}$ vista no tópico anterior, uma equiparação entre normas de direitos fundamentais (princípios) e "valores" que devem ser ponderados. Segundo Habermas, $\mathrm{T}_{\mathrm{PR}}$ implica aceitar que "the deontological understanding of norms can be translated into an equivalent understanding of corresponding value contents" (HABERMAS, 1998, p. 428). Com isso ocorre uma equiparação entre princípios e valores, o que ignora o caráter deontológico dos primeiros. É certo que Alexy assume que há diferença entre o carater nomativo deontológico de princípios e o caráter de preferências do princípios, porém nos casos de conflito entre princípios eles são equiparados a valores para efeitos e ponderação e por isso rejeita uma distinção rígida entre o sentido "deontológico" e "ontológico" de princípios e valores (ALEXY, 1998). Esta afirmação é apoiada numa definição específica do sentido "deontológico" dos princípios, o qual apresenta-se como uma pretensão de validade normativa incondicional que, assumindo a característica do universalismo moral, envolve todos os sujeitos potencialmente capazes de participar em discursos práticos. Com isso Alexy conclui que as

${ }^{11}$ Uma formulação inicial encontra-se em Alexy (1980), posteriormente desenvolvida em Alexy (1993) e recentemente ligeiramente revista em Alexy (2002, 2003a, 2003b). 
normas jurídicas, na medida em que certamente devem pretender ser justificadas com argumentos menos universalistas e mais políticos, contextualizados, empíricos, não podem pretender um caráter exclusivamente deontológico.

O que está em jogo aqui é uma importante questão política sob a forma de disputa semântica: a correta definição do sentido normativo dos princípios. E o motivo pelo qual Habermas rejeita a idéia de ponderação de valores é que ele define tal sentido não por referência à perspectiva universalista da moral, como equivocadamente o faz Alexy, mas sim ao código binário válido/inválido, similar a legítimo/ilegítimo, correto/incorreto, discursivamente justificados. Não se trata de normas justificadas sob a perspectiva universal de todos os potenciais participantes de discursos práticos mas sim vinculados a ordens jurídicas e políticas concretas, as quais podem tratar de temas mais ou menos cocretos e ainda assim pretender validade incondicional. $\mathrm{O}$ mesmo não ocorre com os juízos sobre valores, os quais expressam apenas ordens concretas de preferências:

O modo como nós acessamos nossos valores e decidimos o que é "bom para nós" e o que é "melhor", num determinado momento, muda diariamente. Como pode ser visto quando reduzimos o princípio da igualdade jurídica a um mero bem entre outros, direitos individuais podem ser sacrificados em benefício de objetivos coletivos. Como resultado, nós não vemos que um direito possa "ceder" a outro direito, sem perda de sua validade, quando ocorre um conflito entre ambos. (HABERMAS, 1998, p. 429)

Adotando o procedimento de ponderação é abandonada a pretensão de correção dos juízos normativos, a qual é incompatível com opções valorativas:

A decisão do tribunal é então em sí mesma um julgamento que de maneira mais ou menos adequada reflete uma forma de vida articulando em si mesma na estrutura de uma ordem concreta de valores. Mas essa decisão não é mais relacionada às alternativas de uma decisão correta ou incorreta. Assimilando proposições de "dever" a valorações, é aberta a via para legitimar amplos poderes discricionários. [...] Como resultado, a exigência estrita de que as decisões sejam justificadas também desaparece. (HABERMAS, 1998, p. 430)

Conferido um poder discricionário de decisão ao tribunal, o qual assume a forma de uma decisão sobre preferências valorativas, está configurado o perigo de decisões irracionais (HABERMAS, 1997, p. 314-330) uma vez que 
não existem critérios racionais para resolver conflitos de preferências valorativas. Na rejeição de Habermas ao modelo de Alexy é perceptível a decisiva influência de Ronald Dworkin, o qual pretende sustentar um modelo de interpretação que rejeita a discricionariedade na decisão judicial. Há no entanto diferenças substanciais, as quais serão mencionadas mais adiante.

De modo responder a estas objeções de submissão ao pano de fundo contextual de valorações dos tribunais, e portanto de dissolução de normas em valores, Alexy acrescentou argumentos a $\mathrm{T}_{\mathrm{PV}}$, e a partir de um pressuposto trivial Alexy insere uma distinção controversa. O presuposto trivial, e correto, é que a argumentação jurídica não pode funcionar exclusivamente através da subsunção, produzindo juízos concretos a partir de normas mais abstratas pelo silogismo categórico, o que ocorre nos em casos corriqueiros da interpretação de normas jurídicas relativamente bem definidas. Coisa diferente ocorre nos chamados casos difíceis, nomeadamente o conflito entre princípios. Problemático é contudo o argumento introduzido o qual, além de requerer uma regra de ponderação, sustenta-se em uma classificação nada corriqueira. Se o modelo de solução de conflitos de regras, pela via da subsunção, é um procedimento "lógico", o segundo (ponderação) se assemelha às regras da "aritmética" (ALEXY, 2003b).

O funcionamento da regra de ponderação, expressão do terceiro subprincípio da proporcionalidade (proporcionalidade em sentido estrito), quando dedicada à solução de um conflito entre dois princípios (P1 e P2) apresenta um funcionamento em três estágios. Em primeiro lugar é necessário estabelecer o grau de não realização de $\mathrm{P} 1$, em segundo lugar deve-se estabelecer o grau da importância em realizar P2, e finalmente em terceiro lugar, é necessário responder à questão, a saber, se a importância de satisfazer P2 justifica a não satisfação de P1. Os irracionalismos apontados por Habermas apenas ocorreriam caso não fosse capaz de produzir juízos racionais acerca (1) da intensidade de interferência dos princípios em conflito (2) dos respectivos graus de importância e (3) das relações de importância entre ambos (ALEXY, 2003a, p. 136; ALEXY, 2003b, p. 436).

Alexy crê ser possível afastar essa possibilidade de irracionalismo uma vez que a jurisprudência constitucional alemã forneceria exemplos de decisões as quais realizam intuitivamente a fórmula que trata de apresentar em nível mais abstrato. Um dos exemplos nos quais se apoia trata de decisão do Tribunal Constitucional Federal alemão acerca da constitucionalidade de uma lei que determinava aos fabricantes de cigarro que reservassem um espaço, nas 
embalagens e propagandas do produto, para a divulgação de informações sobre os danos à saúde causados pelo consumo do produto. As empresas fabricantes de cigarro alegavam que o dispositivo feria o princípio constitucional de liberdade de iniciativa ao passo que a administração federal apoiava-se no princípio da proteção à saúde pública. A decisão considerou, neste caso, que a liberdade de iniciativa dos produtores deveria ceder espaço à proteção da saúde pública, de modo que a obrigatoriedade imposta aos fabricantes foi considerada constitucional. (ALEXY, 2003a, ps. 136 e ss.; ALEXY, 2003b, ps. 435 e ss).

Em outro caso tratou-se do conflito entre os princípios da liberdade de expressão e da proteção à personalidade, em caso no qual uma revista humorística utilizou, em duas oportunidades, a fotografia de um militar da reserva, paraplégico, para nele basear alguns de seus textos. Na primeira oportunidade ao militar foi atribuída a menção de "assassino por natureza", ao passo que na segunda foi qualificado como "aleijado". O tribunal considerou que, no primeiro caso, deveria prevalecer o princípio da liberdade de expressão, uma vez que a menção aparecia em contexto tal que permitia supor tratar-se de texto não intencionalmente ofensivo, tratando-se de um texto "reconhecidamente humorístico", entre outras coisas por que a seu lado figurava a imagem do então presidente da República Federal assinalado como "cidadão por natureza". Já no segundo caso coisa distinta ocorria, já que o termo "aleijado", atribuído a um ex-militar cuja deficiência física resultara do exercício das funções institucionais militares, poderia ser considerado como usualmente "humilhante" e expressão de uma "falta de respeito". (ALEXY, 2003a, p. 136; ALEXY, 2003b, p. 435)

A questão inicial é como podem tais juízos serem expressos na fórmula de ponderação. Para Alexy, embora as duas decisões "utilizem valorações que não se encontram diretamente na fórmula de ponderação" ainda assim é possível construir juízos não arbitrários para fixar o grau de interferência dos princípios: "reasons are given for them, and they are understandable." (ALEXY, 2003b, p. 439)

Um intento de formalizar o juízo realizado intuitivamente nos dois casos é oferecido por Alexy nos seguintes termos (ALEXY, 2003a, p. 136137; ALEXY, 2003b, p. 443). Qualificando os graus de interferências numa escala de "leve", "moderada" e "séria", a fórmula da ponderação poderia funcionar e produziria um resultado, concluindo que tais decisões de fato se encaixam na fórmula "aritmética" da ponderação. Os objetos de avaliação 
são: em primeiro lugar $\left(\mathrm{I}_{\mathrm{i}}\right)$, a intensidade da interferência no princípio $\mathrm{P}_{\mathrm{i}}$, a qual será sempre a expressão de uma "quantidade concreta"; em segundo lugar $\left(\mathrm{W}_{\mathrm{i}}\right)$, expressão do valor abstrato de $\mathrm{P}_{\mathrm{i}}$ relativamente aos demais princípios, independente das circunstâncias concretas do caso de aplicação. O próprio Alexy reconhece que esta é uma variável deveras complicada, posto que se muitos princípios pouco diferem quanto ao valor abstrato que possuem outros possuem altíssimo valor, como por ex. o "direito à vida", especialmente quando oposto ao direito geral à liberdade de ação. Em terceiro lugar, é necessário fixar a importância da satisfação de $P_{j}\left(I_{j}\right)$ que também será considerada uma "quantidade concreta", embora Alexy reconheça que ela pudesse expressar também valores abstratos. Assim $\left(I_{j}\right)$ apenas "pode depender dos efeitos os quais a omissão da interferência de $\mathrm{P}_{\mathrm{i}}$ acarretaria para $\mathrm{P}_{2}$ " e neste caso pode ser formalmente expresso nos seguintes termos: $\left(I_{j}\right)$ "é tão grande quanto a intensidade com a qual a não interferência com $\mathrm{P}_{\mathrm{i}}$ interfere com $\mathrm{P}_{\mathrm{j}}$. Isso mostra que o conceito de importância concreta de $\mathrm{P}_{\mathrm{j}}$ é idêntico ao conceito de intensidade da interferência com $\mathrm{P}_{\mathrm{j}}$ pela omissão da interferência com $\mathrm{P}_{\mathrm{i}}$ " (ALEXY, 2003b, p. 441). E uma vez que seja utilizada a escala de leve, moderada e séria, "a questão de como o terceiro passo do balanceamento pode ser resolvida prova ser fácil." (ALEXY, 2003 b, p. 442). Basta comparar as hipóteses que resultam da aplicação de "l", "m" e "s" a $I_{i}$ e $I_{i}$ : para as seguintes hipóteses prevalece $\mathrm{P}_{\mathrm{i}}$ :

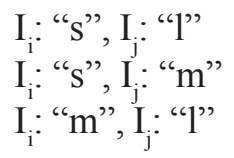

Ao passo que nas seguintes prevalece $\mathrm{P}_{\mathrm{j}}$ :

$I_{i}:$ : l", $I_{j}:$ : $s$ "

$I_{i}:$ "m", $I_{j}:$ "s"

$I_{i}:$ "l", $I_{j}:$ "m"

No entanto, em casos como os seguintes o resultado é um "empate", e sobra espaço à "discrição judicial no balanceamento" para que o legislador atue ou não. (ALEXY, 2002, p. 45 e ss).

$I_{i}:$ "l", $I_{j}:$ "l"
$I_{i}:$ "m", $I_{j}:$ "m"
$I_{i}:$ : $s ", I_{j}:$ "s" 
Assim é possível estabelecer agora o valor concreto de $\mathrm{P}_{\mathrm{i}}$ nos casos de conflito "W $\mathrm{W}_{\mathrm{i}, \mathrm{j}}$ ":

$$
\mathrm{W}_{\mathrm{i}, \mathrm{j}}=\frac{\mathrm{I}_{\mathrm{i}}}{\mathrm{I}_{\mathrm{j}}}
$$

E nos casos de conflito em que os valores abstratos de cada um dos princípios variam $\left(\mathrm{W}_{\mathrm{i}} \mathrm{e} \mathrm{W}_{\mathrm{j}}\right)$, a fórmula deve ser aprimorada:

$$
W_{i, j}=\frac{I_{i} \cdot W_{i}}{I_{j} \cdot W_{j}}
$$

A fórmula no entanto não está completa. Falta ainda inserir um terceiro par de variáveis $\left(\mathrm{R}_{\mathrm{i}}\right.$ e $\left.\mathrm{R}_{\mathrm{i}}\right)$ que correspondem à confiabilidade nas suposições empíricas que são feitas em relação à mensuração das variáveis anteriores nos casos concretos. Uma "segunda lei de ponderação" mestabelece que "the more heavily na interference with a constitutional right weighs, the greater must be the certainty of its underlying premisses" (ALEXY, 2003b, p. 446). Ao contrário da primeira lei da ponderação, a qual se refere às razões substantivas para a interferência entre princípios, esta lei refere-se à qualidade epistémica dos pressupostos que suportam a interferência. Assim, levando em conta as duas leis da ponderação, a fórmula completa adquire a seguinte forma:

$$
\mathrm{W}_{\mathrm{i}, \mathrm{j}}=\frac{\mathrm{I}_{\mathrm{i}} \cdot \mathrm{W}_{\mathrm{i}} \cdot \mathrm{R}_{\mathrm{i}}}{\mathrm{I}_{\mathrm{j}} \cdot \mathrm{W}_{\mathrm{j}} \cdot \mathrm{R}_{\mathrm{j}}}
$$

Ocorre que os valores envolvidos na fórmula de ponderação apenas poderiam funcionar enquanto quocientes "na presença de números", o que não é o caso em se tratando do conflito de princípios jurídicos - reconhece Alexy, e daí que na argumentação jurídica trata-se apenas de uma "analogia" a remissão aos "quocientes" (ALEXY, 2003b, p. 444). Ainda assim pretende que "a fórmula da subsunção representa um esquema que funciona de acordo com as regras da lógica" ao passo que "a fórmula da ponderação de valores representa um esquema que trabalha de acordo com as regras da aritmética" (ALEXY, 2003b, p. 448). Permanece a questão a saber se a referência às regras da aritmética não seria também apenas uma analogia, e em que sentido tal poderia elucidar o 
papel da fórmula apresentada. Afinal, qual o ganho que há na distinção entre "lógica" e "aritmética"? Alexy (2003b, p. 448):

Nem a fórmula da subsunção nem a fórmula de ponderação em nada contribui diretamente para a justificação do conteúdo dessas premissas. Em relação a isso ambos são completamente formais. Mas isso não pode diminuir o valor de identificar o tipo e a forma das premissas as quais são necessárias para justificar o resultado.

Assim, apesar de toda a sofisticação alcançada pela reformulação da regra de ponderação, questão central apontada por Habermas permanece sem resposta. Em primeiro lugar, a fórmula apenas pode funcionar quando aquilo que é mais importante e requer justificação já é tomado como válido: a atribuição de valores "s", "m" e "l". Nos casos citados acima Alexy pôde coletar as valorações já feitas pelo tribunal e, "através" da fórmula da ponderação, concluir que "a intensidade da interferência com estes direitos foi determinada e eles foram colocados em relação entre sí” (ALEXY, 2003a, p. 137). Neles a decisão pode decorrer diretamente de imagens de mundo prévias adoptadas pelo tribunal, de suas opções e valorações ético-políticas acerca do lugar que os contratos de direito privado ocupam numa imagem social de mundo, de sua autoridade e consequente prioridade moral, ou da importância atribuída à liberdade de expressão. O mais importante é justamente essa valoração, sem a qual a ponderação não funciona. Adoptando as valorações do Tribunal Alexy como premissas é possível "aplicar" a regra e concluir com segurança: "sem dúvida alguma, é balanceamento" (ALEXY, 2003a, p. 136). As dúvidas agora recaem "apenas" sobre a atribuição de valores. Os novos argumentos de Alexy de modo algum são uma objeção à crítica dirigida por Habermas: a irracionalidade apontada consiste na atribuição de valores e preferências aos princípios, ou seja, àquilo que as fórmulas de Alexy já devem necessariamente pressupor e sem o que não funcionam. É certo que, realizada a valoração, podemos racionalmente alcançar um resultado, mas não é porém aqui que reside a possibilidade de irracionalidade apontada por Habermas e sim no fato mesmo da valoração. Aliás, é possível mesmo afirmar que, feita a valoração, a fórmula termina por ser de pouca valia, já que sua relação de preferência apenas expressa formalmente aquilo que já se encontra inevitavelmente no significado semântico do texto que expõe as opções de valores (ALEXY, 2003a, p. 139). 


\section{CONSIDERAÇÕES FINAIS}

As críticas lançadas à tese da distinção "lógica" ("estrutural") entre princípios e regras e à tese da "ponderação" não se apóiam na rejeição das pretensões de universalidade do discurso racional. Ao contrário, tais críticas são apoiadas precisamente nas teses mais elementares da teoria do discurso. No entanto, levam à conclusão de que as "regras de ponderação", fornecidas por Alexy, não são capazes de "criar" uma relação entre juízos sobre o grau de intensidade e proporcionalidade.

Seguramente tais regras podem pretender funcionar como um guia para argumentações jurídicas, prescrevendo como as valorações lançadas pelo tribunal deveriam ser mantidas em referência umas às outras. Mas, por outro lado, isto não significa que, rigorosamente falando, elas "criem" algo, pois apenas se limitam a expressar em grau muito mais elevado de abstração algo que já está disponível numa decisão particular. Isso é ainda mais evidente na medida em que são os exemplos de Alexy são usados para mostrar o significado das fórmulas abstratas, quando deveria poder ser exigido o oposto, ou seja, que tais fórmulas abstratas mostrassem como resolver casos concretos com base nas fórmulas. E, neste ponto, é impossível deixar de lado o dito famoso de Oliver Wendell Holmes: "afirmações abstratas não decidem casos concretos" (HOLMES, 1993, p. 26). Após valorarmos em grave, médio e leve o grau de importância de cada princípio e de sua correspondente não realização, já não precisaríamos mais das fórmulas, pois bastaria o uso ordinário da linguagem. Como foi visto acima, Alexy parece perceber este problema ${ }^{12}$, mas ainda assim pretende que a formulação da regra de proporcionalidade seja uma resposta satisfatória à crítica de Habermas. Em outras palavras, é como se Habermas afirmasse: "a interpretação de princípios pela via do modelo de ponderação possibilita decisões que resultam diretamente das opções valorativas adoptadas pelo tribunal", e diante de tal crítica, a reposta fornecida por Alexy fosse: "a ponderação é racional, pois, dadas as valorações, é possível alcançar uma conclusão racional usando a regra de ponderação". A resposta fornecida apenas confirma a crítica que lhe é dirigida.

12 "of course, such judgments presuppose standards that are not themselves to be found in the law of balancing". Mas ainda assim isso não significa que Habermas esteja correto quanto à irracionalidade do procedimento, pois "reasons are given form them, and they are understandable." (ALEXY, 2003b, p. 439).

REVISTA DO DIREITO PÚBLICO, Londrina, v.8, n.3, p.167-192, set./dez.2013 


\section{REFERÊNCIAS}

AARNIO, Aulis. Las Reglas en Sério. In: . La normatividad del derecho. Barcelona: Gedisa, 1997. p. 17-35.

AARNIO, Aulis. Reason and Authority: a treatise on the dynamic paradigm of legal dogmatics. Cambridge: Dortmouth/Arshgate, 2002.

AARNIO, Aulis; VALDÉS, Ernesto G.; Jyrki UUsitalo (Org.). La normatividad del derecho. Barcelona: Gedisa, 1997.

ALEXY, Robert. Constitutional Rights, Balancing, and Rationality. Ratio Juris. Oxford, v. 16, n. 2, p. 131-140, 2003 a.

ALEXY, Robert. Die Logische Analyse Juristischer Entscheidungen. Archiv für Rechts - und Sozialphilosophie, Beiheft, n. 14, p. 181-212,1980.

ALEXY, Robert. El Concepto y la Validez del Derecho. Gedisa: Barcelona, 1994.

ALEXY, Robert. Epílogo a la Teoria de los Derechos Fundamentales. Revista Española de Derecho Constitucional, Madrid, n. 66, p. 13-65, 2002.

ALEXY, Robert. Jürgen Habermas's Theory of Legal Discourse. In: ROSENFELD, Michel; ARATO, Andrew. Habermas on Law and Democracy. California: University of California Press, 1998. p. 226-233.

ALEXY, Robert. On Balancing and Subsumption: a structural comparision. Ratio Juris, Oxford, v. 16, n. 4, p. 433-499, 2003 b.

ALEXY, Robert. On the Structure of Legal Principles. Ratio Juris, Oxford, v. 13, n. 3, p. 294-304, 2000.

ALEXY, Robert. Sistema Jurídico y Razon Practica. In ALEXY, Robert. El Concepto y la Validez del Derecho. Gedisa: Barcelona, 1994. ps. 159-177. 
ALEXY, Robert. Teoria de los Derechos Fundamentales. Madrid: Centro de Estudios Constitucionales, 1993.

ARROYO, Juan Carlos Velasco. La Teoría Discursiva del Derecho: sistema jurídico y democracia en Habermas. Madrid: Centro de Estudios Politicos e Constitucionais, 2000.

ATIENZA, Manuel. As Razões do Direito: teorias da argumentação jurídica. Belo Horizonte: Landy, 2000.

ATIENZA, Manuel; MANERO, Juan Ruiz. Sobre Princípios y Reglas. Doxa, Alicante,v. 10, p. 101-120, 1991.

ÁVILA, Humberto. Teoria dos Princípios: da definição à aplicação dos princípios jurídicos. 4. ed. São Paulo: Malheiros, 2004.

BRASIL. Código Tributário Nacional. Lei $n^{0}$ 5.172/66. Disponível em:<www.brasil.gov.br>. Acesso em: 05 nov. 2013.

BRASIL. Decreto-Lei $\mathbf{n}^{\mathbf{0}}$ 4.657, de 4 de Setembro de 1942. Lei de Introdução às Normas do Direito Brasileiro Disponível em:<www.brasil.gov.br>. Acesso em: 5 nov. 2013.

DWORKIN, Ronald. Levando os Direitos a Sério. São Paulo: Martins Fontes, 2002.

DWORKIN, Ronald. O Direito como Integridade. São Paulo: Martins Fontes, 1999.

ESSER, Josef., Josef. Princípio y Norma en la Elaboración Jurisprudencial del Derecho Privado. Barcelona: Bosch, 1961.

GÜNTHER, Klaus. The Sense of Appropriateness. New York: Harvard University Press, 2001.

HABERMAS, Jürgen. Direito e Democracia: entre facticidade e validade. Rio de Janeiro: Tempo Brasileiro, 1997. 2 v. 
HABERMAS, J. Reply to Symposium Participants. In: ARATO, Andrew; ROSENFELD, Michel. Habermas on Law and Democracy: critical exchanges. Berkeley: University of California Press, 1998. p. 381-452.

HABERMAS, Jürgen. A short Reply. Ratio Juris, Oxford, v. 12, n. 4, p. 445 453, 1999.

HART, H. O Conceito de Direito. 2. ed. Lisboa: Calouste Gulbenkian, 1994.

HOLMES, O. W. Voto dissentindo, no caso Lochner v. New York, 198 U.S. 45 (1905). In FISCHER III, William; HORWITZ, Morton; REED, Thomas (Org.). American Legal Realism. New York: Oxford University Press, 1993. p. 26.

KANT, Immanuel. Sobre um Suposto Direito de Mentir por Amor à Humanidade. In: Edições 70, 1995. p. 173-179. A paz perpétua e outros opúsculos. Lisboa:

MUÑIS, Joaquín R.-Toubes. Legal Principles and Legal Theory. Ratio Júris, Oxford, v. 10, n. 3, p. 267-287, 1997.

PECZENIK, Aleksander. On Law and Reason. Dordrecht: Kluwer, 1989. RAZ, Joseph (Org.). Practical Reasoning. Oxford: Oxford University Press, 1978.

ROSS, W. D. The Right and the Good. Idianápolis: Hackett, 1988.

SEARLE, John. Prima Facie Obligations. In: RAZ, Joseph (Org.). Practical Reasoning. Oxford: Oxford University Press, 1978. p. 81-90.

SEARLE, John. Razones para Actuar. Oviedo: Nobel, 2000.

SILVA, Luís Virgílio Afonso da. O Proporcional e o Razoável. Revista dos Tribunais, São Paulo, v. 91, n. 798, p. 23-50, 2002. 
WALDRON, Jeremy. Did Dworkin Ever Answer the Crits? In: HERSHOVITZ, Scott (Org). Exploring Law's Empire: the jurisprudence of Ronald Dworkin. Oxford: Oxford University Press, 2006. p. 155-181.

Artigo recebido em: 06/11/2013 Aprovado para a publicação em: 02/12/2013

Como citar: OLIVEIRA, Cláudio Ladeira. Princípios, regras e ponderação: uma polêmica no âmbito da teoria discursiva do Direito. Revista do Direito Público. Londrina, v.8, n.3, p.167-192, set./dez. 2013. DOI: 10.5433/1980$511 X .2013 v 8 n 3 p 167$. 